О.Г. Закапко ${ }^{1}$ М.А. Подригало ${ }^{2}$ К.Г. Яценко ${ }^{1}$

${ }^{1}$ Харківський начіональний університет Повітряних Сил ім. І. Кожедуба, Харків

${ }^{2}$ Наџіональна академія Національної гвардї України, Харків

\title{
ВИБІР РАЦІОНАЛЬНИХ ПАРАМЕТРІВ КЕРМОВОГО ПРИВОДУ ПЕРСПЕКТИВНОГО ТРАКТОРНОГО САМОХІДНОГО ШАСІ
}

У даній статті, на прикладі кермового приводу перспективного тракторного самохідного шасі проведено рачіональний вибір геометрії важільного механізму за критерієм коефіцієнту корисної дії. Метою статті є підвищення коефіџієнта корисної дї кермового приводу тракторного самохідного шасі з переднім поворотним мостом иляхом раціонального вибору його геометричних параметрів. Визначено кут початкової установки поворотного важеля. Отримано аналітичні вирази для визначення ходу штока силового гідроциліндра і крутного моменту, створюваного силовим гідроциліндром. Визначено робота сил тертя в шарнірі, який з'єднує поворотний важіль зі штоком силового гідроциліндра, що дозволило визначити иикловий коефіцієнт втрат на тертя в кермовому приводі. Визначено значення рачіонального кута початкової установки поворотного важеля. Встановлено, що при обраному куті початкової установки поворотного важеля втрати на тертя в кермовому приводі знижуються. Застосування кермового приводу з двома силовими гідрочиліндрами дозволяе вирівняти робочі тиски рідини при повороті, як вправо так $і$ вліво, зменшити циклові втрати на тертя при куті початкової установки поворотного двохплечового важеля.

Ключові слова: тракторне самохідне шасі з поворотним переднім мостом, поворотний міст, коефіцієнт корисної дії, кермовий привід, силовий гідрочиліндр, геометричні параметри кермового приводу.

\section{Вступ}

Постановка проблеми. Тракторні самохідні шасі набули широкого застосування в різних галузях промисловості і сільського господарства. У Повітряних Силах Збройних Сил України ці машини використовуються для ремонту твердих покриттів аеродромів і можуть бути задіяні в технологічному процесі обслуговування літаків [1-2].

У конструкціях сучасних колісних тракторів, в тому числі і тракторних самохідних шасі, в даний час використовуються гідрооб’ємні кермові управління. Кермовий привід являє собою традиційну кермову трапецію, запропоновану ще у 1893 році Карлом Бенцом і приводиться в дію силовим гідроциліндром. Компонування переднього мосту самохідного шасі дозволяє здійснювати його поворот в процесі здійснення маневрів, що забезпечує рух лівого і правого коліс без бокового ковзання при будь-якій змінній колії [3].

Ця стаття присвячена визначенню раціональних геометричних параметрів кермового приводу перспективного тракторного самохідного шасі з поворотним переднім мостом.

Аналіз останніх досліджень і публікацій. Кермовий привід автомобіля виконаний, у вигляді трапеції, запропонував К. Бенц ще у 1893 році.

Застосування кермової трапеції забезпечує близьке до ідеального співвідношення кутів повороту лівого і правого коліс, що дозволило зробити рево- люційний стрибок у розвитку конструкції автомобіля. Однак певну похибку у позиціонуванні напрямних коліс кермова трапеція все-таки створює. Вплив кінематичної похибки кермового приводу тракторного самохідного шасі на додаткові витрати потужності двигуна при повороті досліджено в роботах [4-7].

У зазначених роботах відзначається значне збільшення кінематичної похибки кермового приводу при зміні колії передніх коліс. Зміна колії обумовлено агротехнічними вимогами що висуваються при виконанні різних технологічних операцій.

Дослідженню керованості колісних тракторів і самохідних шасі присвячені численні роботи [6-10]. $\mathrm{y}$ цих роботах значна увага приділена підвищенню керованості колісних машин.

Показники цієї експлуатаційної властивості в значній мірі залежать від забезпечення кінематичної точності повороту колісних машин. На жаль, наявність кермової трапеції призводить до збільшення опору руху машини і додатковим енергетичним витратам [11-12].

Застосування передньої поворотної (направляючої) осі дозволяє підвищити кінематичну точність повороту колісної машини і знизити непродуктивні витрати енергії двигуна [13-15].

Здійснення повороту самохідного шасі за рахунок зміни положення переднього моста дозволяє забезпечити “ідеальний” поворот при будь-якій колії передніх коліс. 
Нами запропонований кермовий привід поворотного моста, який представляє собою важільний механізм, що приводиться у дію силовим гідроциліндром (рис. 1).

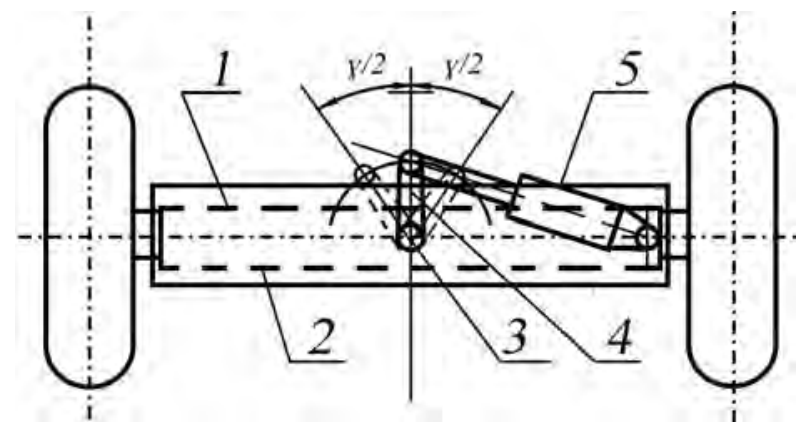

Рис. 1. Кінематична схема кермового приводу переднього поворотного мосту перспективного тракторного самохідного шасі:

1 - передній поворотний міст;

2 - передній брус рами;

3 - вертикальний вал приводу поворотного моста;

4 - поворотний важіль;

5 - силовий циліндр;

$\gamma$ - максимальний кут повороту переднього мосту

Джерело: розроблено авторами.

Керованість самохідного шасі залежить від швидкодії кермового приводу і витрат енергії на здійснення повороту переднього мосту. Коефіцієнт корисної дії кермового приводу, представленого на (рис. 1), залежить від вибору геометрії його ланок.

Мета статті - підвищення коефіцієнта корисної дії кермового приводу тракторного самохідного шасі $з$ переднім поворотним мостом шляхом раціонального вибору його геометричних параметрів.

Для досягнення поставленої мети необхідно вирішити такі завдання:

- визначити взаємозв'язок між геометричними параметрами кермового приводу і кутом повороту направляючого моста;

- здійснити вибір оптимального початкового кута установки поворотного важеля кермового приводу.

\section{Виклад основного матеріалу}

\section{Визначення взаємозв'язку між геометричними параметрами кермового приводу і кутом повороту направляючого мосту}

Геометричні параметри розглянутого кермового приводу при поточному і крайніх положеннях поворотного важеля представлені на рис. 2.

Кут $\theta$ (гострий кут між осями симетрії поворотного важеля і штока силового гідроциліндра) може бути визначено з використанням теореми синусів

$$
\frac{A}{\sin \theta}=\frac{h}{\sin \left(90^{0}+\alpha-\beta_{0}\right)}=\frac{R}{\sin \delta},
$$

де $\alpha$ - кут повороту важеля;

$\beta_{0}$ - кут початкової установки поворотного важеля; вимірюється відносно поздовжньої осі трактора;

$\delta$ - кут нахилу осі силового циліндра до відрізку $(\overline{\mathrm{OA}})$;

$R$ - довжина поворотного важеля. Враховуючи, що

$$
\delta+\theta+90^{0}+\alpha-\beta_{0}=180^{0},
$$

знаходимо

$$
\operatorname{tg} \theta=\frac{\cos \left(\alpha-\beta_{0}\right)}{\frac{R}{A}+\sin \left(\alpha-\beta_{0}\right)},
$$

або

$$
\theta=\operatorname{arctg} \frac{\cos \left(\alpha-\beta_{0}\right)}{\frac{R}{A}+\sin \left(\alpha-\beta_{0}\right)} .
$$

Початкове значення кута $\theta$ (при $\alpha=0$ ):

$$
\theta=\theta_{0}=\operatorname{arctg} \frac{\cos \beta_{0}}{\frac{R}{A}-\sin \beta_{0}} .
$$

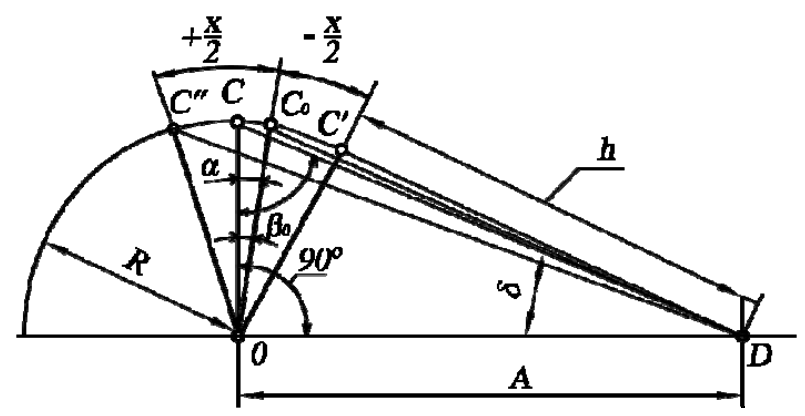

Рис. 2. Геометричні параметри кермового приводу при різних положеннях поворотного важеля Джерело: розроблено авторами.

Значення кута $\theta$ при крайніх положеннях ( $\alpha=\frac{Y}{2}$ або $\alpha=-\frac{Y}{2}$ ) поворотного важеля

$$
\begin{aligned}
\theta_{1}=\operatorname{arctg} \frac{\cos \left(\frac{Y}{2}-\beta_{0}\right)}{\frac{R}{A}+\sin \left(\frac{Y}{2}-\beta_{0}\right)}, \text { npu } \quad \alpha=\frac{Y}{2}, \\
\theta_{2}=\operatorname{arctg} \frac{\cos \left(\frac{Y}{2}+\beta_{0}\right)}{\frac{R}{A}-\sin \left(\frac{Y}{2}+\beta_{0}\right)}, n p u \quad \alpha=-\frac{Y}{2} .
\end{aligned}
$$

Поточне значення відстані між точками кріплення силового гідроциліндра 


$$
\begin{gathered}
h=A \frac{\cos \left(\alpha-\beta_{0}\right)}{\sin \theta} \times \\
\times \sqrt{\cos ^{2}\left(\alpha-\beta_{0}\right)+\left[\frac{R}{A}+\sin \left(\alpha-\beta_{0}\right)\right]^{2}}
\end{gathered}
$$

Початкове при $(\alpha=0)$ відстань між точками кріплення силового гідроциліндра

$$
h_{0}=A \sqrt{\cos ^{2} \beta_{0}+\left(\frac{R}{A}-\sin \beta_{0}\right)^{2}} .
$$

При крайньому розташуванні точок кріплення силового гідроциліндра

$$
h_{\text {лів }}=A \sqrt{\cos ^{2}\left(\frac{Y}{2}-\beta_{0}\right)+\left[\frac{R}{A}+\sin \left(\frac{Y}{2}-\beta_{0}\right)\right]^{2}} \text {, }
$$

при $\alpha=\frac{Y}{2}$;

$$
h_{\text {прав }}=A \sqrt{\cos ^{2}\left(\frac{Y}{2}+\beta_{0}\right)+\left[\frac{R}{A}-\sin \left(\frac{Y}{2}+\beta_{0}\right)\right]^{2}},
$$

при $\alpha=-\frac{Y}{2}$.

3 виразу (3) знаходимо

$$
\sin \theta=\frac{\cos ^{2}\left(\alpha-\beta_{0}\right)}{\sqrt{\cos ^{2}\left(\alpha-\beta_{0}\right)+\left[\frac{R}{A}+\sin \left(\alpha-\beta_{0}\right)\right]^{2}}},
$$

а також

$$
\cos \theta=\frac{\sin \theta}{\operatorname{tg} \theta}=\frac{\frac{R}{A}+\sin \left(\alpha-\beta_{0}\right)}{\sqrt{\cos ^{2}\left(\alpha-\beta_{0}\right)+\left[\frac{R}{A}+\sin \left(\alpha-\beta_{0}\right)\right]^{2}}}
$$

Крутний момент $M_{n о в}$, створюваний силовим гідроциліндром дорівнює моменту опору $M_{c y n p}$ повороту мосту

$$
\begin{gathered}
M_{\text {nов }}=M_{c y n p}=P_{u m} \cdot R \times \\
\times \frac{\cos \left(\alpha-\beta_{0}\right)}{\sqrt{\cos ^{2}\left(\alpha-\beta_{0}\right)+\left[\frac{R}{A}+\sin \left(\alpha-\beta_{0}\right)\right]^{2}}},
\end{gathered}
$$

де $P_{u m}$ - зусилля на штоку силового гідроциліндра.

Припустимо, що момент опору повороту переднього моста величина постійна.

Це означає, що при повороті важеля змінюється зусилля на штоку гідроциліндра. Закон зміни зазначеного зусилля визначимо з рівняння (14)
$P_{u m}=\frac{M_{c y n p}}{2 \cdot \sin \theta}=\frac{M_{c y n p}}{R} \sqrt{1+\left[\frac{\frac{R}{A}+\sin \left(\alpha-\beta_{0}\right)}{\cos \left(\alpha-\beta_{0}\right)}\right]^{2}}$.

\section{Вибір раціонального початкового кута установки поворотного важеля}

Коефіцієнт корисної дії кермового приводу визначається втратами на тертя в шарнірі, що з'єднує поворотний важіль зі штоком силового гідроциліндра. Вертикальний вал 3 (рис. 1) приводу поворотного мосту, встановлений на підшипниках кочення, втрати в яких постійні і незначні в порівнянні 3 втратами в сполучному шарнірі. Зазначеними втратами можна знехтувати.

Робота сил тертя у сполучному шарнірі

$$
A_{m e p}^{\text {лiв }}=2 \int_{\theta_{0}}^{\theta_{1}} M_{m e p} d \theta=2 \int_{\theta_{0}}^{\theta_{1}} P_{u} \mu \frac{d_{u}}{2} d \theta,
$$

при повороті вліво;

$$
A_{m e p}^{\text {nрав }}=2 \int_{\theta_{0}}^{\theta_{2}} M_{m e p} d \theta=2 \int_{\theta_{0}}^{\theta_{2}} P_{u} \mu \frac{d_{u}}{2} d \theta,
$$

при повороті вправо,

де $\mu$ - коефіцієнт тертя в кінематичній парі;

де $M$ - коефіцієнт тертя в кінематичній парі;

$d_{u}$ - діаметр шарніра.

Після підстановки рівняння (15) у вираз (16) i (17) отримаємо:

$$
\begin{aligned}
& A_{\text {mep }}^{\text {лiв }}=\frac{M_{c y n p} \mu d_{u}}{R} \int_{\theta_{0}}^{\theta_{1}} \operatorname{cosec} \theta d \theta= \\
& =\frac{M_{c y n p} \mu d_{u}}{R}|\ln | \operatorname{tg} \frac{\theta_{1}}{2}|-\ln | \operatorname{tg} \frac{\theta_{0}}{2}|| ; \\
& A_{\text {mep }}^{\text {npas }}=\frac{M_{c y n p} \mu d_{u}}{R} \int_{\theta_{0}}^{\theta_{2}} \operatorname{cosec} \theta d \theta= \\
& =\frac{M_{c y n p} \mu d_{u}}{R}|\ln | \operatorname{tg} \frac{\theta_{2}}{2}|-\ln | \operatorname{tg} \frac{\theta_{0}}{2}|| .
\end{aligned}
$$

У рівняннях (18) і (19) знаки абсолютної величини введені з метою запобігання отримання негативної роботи.

Корисна робота, що здійснюється при повороті переднього моста

$$
A_{\kappa o p}=2 \int_{0}^{\gamma / 2} M_{c y n p} d \alpha=M_{c y n p} \cdot \gamma
$$

Цикловий коефіцієнт втрат на тертя в кермовому механізмі:

$$
\left(\Psi_{\text {тер }}^{\text {лів }}\right)_{\text {цикл }}=\frac{A_{\text {mер }}^{\text {лів }}}{A_{\kappa о р}}=\frac{\mu \cdot d_{u}}{R \cdot \gamma}|\ln | \operatorname{tg} \frac{\theta_{1}}{2}|-\ln | \operatorname{tg} \frac{\theta_{0}}{2}||,
$$




$$
\left(\Psi_{\text {тер }}^{\text {прав }}\right)_{\text {цикл }}=\frac{A_{\text {mер }}^{\text {прав }}}{A_{\kappa о р}}=\frac{\mu \cdot d_{u}}{R \cdot \gamma}|\ln | \operatorname{tg} \frac{\theta_{2}}{2}|-\ln | \operatorname{tg} \frac{\theta_{0}}{2} \|
$$

3 урахуванням співвідношень (6) і (7) вирази (21) і (22) приймуть вигляд:

$$
\begin{aligned}
& \left(\Psi_{\text {тер }}^{\text {лів }}\right)_{\text {цикл }}= \\
& =\frac{\mu \cdot d_{u}}{R \cdot \gamma}|\ln | \operatorname{tg}\left[0,5 \operatorname{arctg} \frac{\cos \left(\frac{\gamma}{2}-\beta_{0}\right)}{\frac{R}{A}+\sin \left(\frac{\gamma}{2}-\beta_{0}\right)}\right]|-| \\
& \left(\Psi_{\text {тер }}^{\text {прав }}\right)_{\text {чикл }}=\frac{\mu \cdot d_{u}}{R \cdot \gamma}|\ln | \operatorname{tg}\left[0,5 \operatorname{arctg} \frac{\cos \left(\frac{\gamma}{2}+\beta_{0}\right)}{\frac{R}{A}-\sin \left(\frac{\gamma}{2}+\beta_{0}\right)}\right] \mid
\end{aligned}
$$

На рис. 3 наведені графіки залежностей циклового коефіцієнта втрат на тертя кермового приводу від кута $\beta_{0}$ установки поворотного важеля. Розрахунки виконані для перспективного тракторного самохідного шасі.

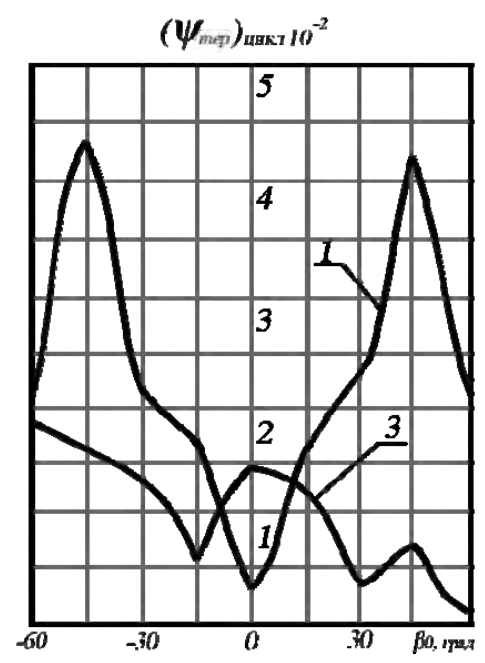

Рис. 3. Залежність циклового коефіцієнта втрат на тертя кермового приводу при $\frac{R}{A}=0,275$; $\gamma=40^{0} ; d_{u}=30 \mathrm{мм} ; R=165$ мм; $\mu=0,15$ :

$$
\text { 1- }\left(\Psi_{\text {тер }}^{\text {лів }}\right)_{\text {чиккл }} .2-\left(\Psi_{\text {тер }}^{\text {прав }}\right)_{\text {циикл }}
$$

Джерело: розроблено авторами.

Аналіз графіків, наведених на рис. 3, дозволяє зробити наступні висновки:

- при повороті вліво найменше значення циклового коефіцієнта втрат забезпечується при $\beta_{0}=0$, а при повороті вправо - при $\beta_{0}=60^{0}$;

- оскільки поворот вправо здійснюється зусиллям, створюваним в штоковій порожнині гідроциліндра при більшому, ніж в безштоковій порожнині тиску рідини, то вибір кута установки $\beta_{0}$ потрібно здійснювати за умовою отримання $\left[\left(\Psi_{\text {тер }}^{\text {лів }}\right)_{\text {циклл }}\right] \min$;

- максимальні значення циклового коефіцієнта втрат на тертя у кермовому приводі можуть досягати (при різних варіантах початкової установки поворотного важеля) 4,3\% - при повороті вліво і 1,8\% при повороті вправо;

- мінімальні значення циклового коефіцієнта втрат на тертя складають при повороті вліво - 0,36\% и при повороті вправо - 0,14\%.

Таким чином, раціональною $є$ величина $\beta_{0}=30^{0}$ (напрямок кута $\beta_{0}$ позитивний за годинниковою стрілкою - див. рис. 2). В цьому випадку $\left(\Psi_{\text {тер }}^{\text {лів }}\right)_{\text {цикл }}=0,022$ (22\%) i $\left(\Psi_{\text {тер }}^{\text {прав }}\right)_{\text {циикл }}=0,0035$

(0,35\%). Якщо використовувати два силові гідроциліндри (див. рис. 4), розташованих симетрично щодо переднього бруса самохідного шасі та двохплечового важеля, то ми отримаємо, що $\left(\Psi_{\text {тер }}^{\text {лів }}\right)_{\text {цчикл }}=\left(\Psi_{\text {тер }}^{\text {прав }}\right)_{\text {цุикл }}$.

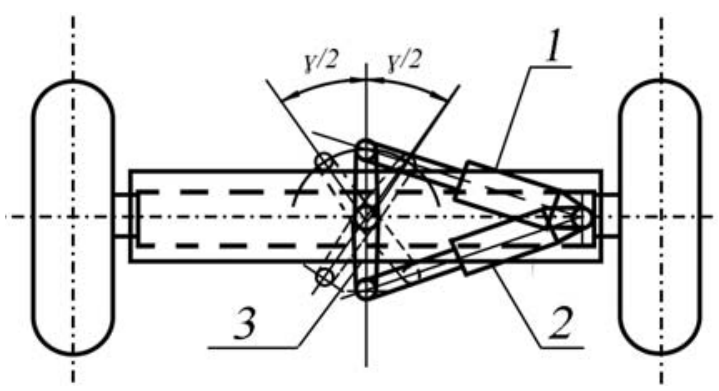

Рис. 4. Кінематична схема кермового приводу 3 двома силовими гідроциліндрами 1 і 2 (3 - друге плече поворотного важеля).

Джерело: розроблено авторами.

Зусилля буде створюватися тільки у безштокових порожнинах силових гідроциліндрів, як при повороті вправо, так і вліво. Цикловий коефіцієнт втрат, як для повороту вліво, так і для повороту вправо буде визначатися залежністю (23) (крива 1 на рис. 3). Кут початкової установки поворотного важеля в цьому випадку буде $\beta_{0}=0$, що відповідає його положенню на (рис. 4).

\section{Висновки}

1. Розроблений метод дозволив здійснити вибір оптимального кута початкової установки поворотного важеля кермового приводу перспективного 
тракторного самохідного шасі. Величина зазначеного кута становить $\beta_{0}=30^{0}$ (позитивний напрямокза годинниковою стрілкою).

2. Максимальні величини циклового коефіцієнта втрат на тертя в кермовому приводі можуть досягати $4,3 \%$.

При обраному куті початкової установки поворотного важеля ці втрати становлять:

- при повороті вліво - 2,2\%;
- при повороті вправо - 0,35\%.

3. Застосування кермового приводу з двома силовими гідроциліндрами дозволяє вирівняти робочий тиск рідини при повороті вправо і вліво, зменшити циклові втрати на тертя до 0,36\% при куті початкової установки поворотного двохплечового важеля $\beta_{0}=0$.

\section{Список літератури}

1. Кириченко В.В. Рішення проблемних задач перспектив розвитку засобів аеродромно-технічного обслуговування повітряних суден / В.В. Кириченко, В.В. Кав’юк, Б.Г. Васильєв // Наука і техніка Повітряних Сил Збройних Сил України. - 2017. - № 2(27). - C. 42-48. https://doi.org/10.30748/nitps.2017.27.07.

2. Толубко В.Б. Перспективи підвищення мобільності й безаварійно техніки за рахунок рішення проблеми маневреності / В.Б. Толубко, Б.Г. Васильєв, А.М. Березан // Системи озброєння і військова техніка. - 2009. - № 4(20). - С. 62-66.

3. Williams M. Traktory Swiata / M. Williams. - Lincoln: “Parragon books LTD”, 2007. - 320 c.

4. Маневренность и тормозные свойства колесных машин / М.А. Подригало, В.П. Волков, В.И. Кирчатый, А.А. Бобошко. - Х.: ХНАДУ, 2003. - 403 с.

5. Стабильность эксплуатационных свойств колесных машин / М.А. Подригало, В.П. Волков, В.А. Карпенко, Е.М. Гецович, А.А. Бобошко, В.М. Ефимчук, А.Н. Матырин. - Х.: ХНАДУ, 2003. - 614 с.

6. Кав’юк В.В. Інноваційна технологія керування поворотом автопоїзда для буксирування штовханням одновісного причепа, приєднаного шарнірно до тягача попереду / В.В. Кав’юк, Б.Г. Васильєв // Системи озброєння і військова техніка. - 2016. - № 4(48). - С. 22-25.

7. Бобошко А.А. Повышение маневренности колесных тракторов и самоходных шасси: дис. ... канд. тех. наук: 05.22.02 / Бобошко Александр Андреевич. - Харьков, 2002. - 239 с.

8. Шарипов В.М. Конструирование и расчет тракторов / В.М. Шарипов. - М.: Машиностроение, 2004. - 592 с.

9. Бучок В.С. Трактори і автомобілі / В.С. Бучок. - К.: Аграрна освіта, 2008. - 331 с.

10. Подригало М.А. Управляемость и устойчивость автомобиля / М.А. Подригало // Автомобильная промышленость. - 2008. - № 11. - С. 22-23.

11. Лебедєв А.Т. Трактори та автомобілі: Ч. З. Шасі / А.Т. Лебедєв, В.М. Атанценков, М.Ф. Бойко. - К.: Вища школа, 2004. - 336 с.

12. Кашканов А.А. Спеціалізований рухомий склад автомобільного транспорту / А.А. Кашканов, В.М. Ребедайло. Вінниця: ВДТУ, 2002. - 164 с.

13. Kryvokon A.G. Kharkiv plant of self-propelled chassis - the producer of unique non-classic layout tractors / A.G. Kryvokon // Scientific Journal “Science Rise”. - № 4(9). - 2015. - P. 50-54. https://doi.org/10.15587/23138416.2015.40448.

14. Ishlinsky A.Yu. Self-Propelled Chassis / A.Yu. Ishlinsky. - M.: Soviet Encyclopedia, 1989. - 656 p.

15. Офіційний сайт VOSTOKAGRO.INFO Assembly tractors [Electronic resource]. - Режим доступу: https://vostokagro.info/dokumentatsiya/156-2009-12-02-12-19-23.html.

\section{References}

1. Kirichenko, V.V., Kav’yuk, V.V., and Vasilev, B.G. (2017), "Rishennya problemnih zadach perspektiv rozvitku zasobiv aerodromno-tehnichnogo obslugovuvannya povitryanih suden" [Solving problematic problems of prospects for the development of aerodrome maintenance of aircraft], Science and Technology of the Air Force of Ukraine, No. 2(27), pp. 42-48. https://doi.org/10.30748/nitps.2017.27.07.

2. Tolubko, V.B., Vasilev, B.G. and Berezan, A.M. (2009), "Perspektivi pidvischennya mobilnosti y bezavariyno tehniki za rahunok rishennya problemi manevrenosti” [Prospects for increasing mobility and trouble-free equipment by solving the problem of maneuverability], Systems of Arms and Military Equipment, No. 4(20), pp. 62-66.

3. Williams, M. (2007), Traktory Swiata, Lincoln, Parragon books LTD, Lincoln, 320 p.

4. Podrigalo, M.A., Volkov, V.P., Kirchatyiy, V.I., and Boboshko, A.A. (2003), "Manevrennost i tormoznyie svoystva kolesnyih mashin" [Maneuverability and braking properties of wheeled vehicles], Izdatelstvo HNADU, Kharkiv, 403 p.

5. Podrigalo, M.A., Volkov, V.P., Karpenko, V.A., Getsovich, E.M., Boboshko, A.A., Efimchuk, V.M., and Matyirin, A.N. (2003), "Stabilnost ekspluatatsionnyih svoystv kolesnyih mashin" [Stability of operational properties of wheeled vehicles], Izdatelstvo HNADU, Kharkiv, 614 p.

6. Kav’yuk, V.V. and Vasilev, B.G. (2016), “Innovatsiyna tehnologiya keruvannya povorotom avtopoyizda dlya buksiruvannya shtovhannyam odnovisnogo prichepa, priednanogo sharnirno do tyagacha poperedu” [Innovative technology to control the rotation of a road train for towing by pushing a single-axle trailer hinged to the tractor in front], Systems of Arms and Military Equipment, No. 4(48), pp. 22-25.

7. Boboshko, A.A. (2002), "Povyishenie manevrennosti kolesnyih traktorov i samohodnyih shassi” [Improving the maneu- 
verability of wheeled tractors and self-propelled chassis], Kharkiv, 239 p.

8. Sharipov, V.M. (2004), "Konstruirovanie i raschet traktorov" [Design and calculation of tractors], Mashinostroenie, Moscow, 592 p.

9. Buchok, V.S. (2008), “Traktori i avtomobili” [Tractors and cars], Agrarna osvita, Kyiv, 331 p.

10. Podrigalo, M.A. (2008), "Upravlyaemost i ustoychivost avtomobilya” [Manageability and stability of the car], Automotive Industry, No. 11, pp. 22-23.

11. Lebedev, A.T., Atantsenkov, V.M., and Boyko, M.F. (2004), "Traktori ta avtomobili. Chassi" [Tractors and cars. Chassis], Vischa shkola, Kyiv, 205 p.

12. Kashkanov, A.A. and Rebedailo, V.M. (2002), "Spetsializovaniy ruhomiy sklad avtomobilnogo transportu: konstruktsiya” [Specialized rolling stock of motor transport], VDTU, Vinnitsya, 164 p.

13. Kryvokon, A.G. (2015), Kharkiv plant of self-propelled chassis - the producer of unique non-classic layout tractors, ScienceRise, No. 4(9), pp. 50-54. https://doi.org/10.15587/2313-8416.2015.40448.

14. Ishlinsky, A.Yu. (1989), Self-Propelled Chassis, Soviet Encyclopedia, Moscow, 656 p.

15. The official site of VOSTOKAGRO.INFO (2019), Assembly tractors, available at: https://vostokagro.info/dokumentatsiya/156-2009-12-02-12-19-23.html.

Надійшла до редколегії 24.02.2020

Схвалена до друку 10.03.2020

\section{Відомості про авторів:}

\section{Закапко Олександр Григорович}

заступник начальника

Харківського національного університету

Повітряних Сил ім. I. Кожедуба,

Харків, Україна

https://orcid.org/0000-0001-6934-2568

\section{Подригало Михайло Абович}

доктор технічних наук професор головний науковий співробітник

Національної академії

Національної гвардії України,

Харків, Україна

https://orcid.org/0000-0002-1624-5219

\section{Яценко Костянтин Григорович}

кандидат технічних наук

доцент

Харківського національного університету

Повітряних Сил ім. І. Кожедуба,

Харків, Україна

https://orcid.org/0000-0001-7822-8521

\section{Information about the authors:}

Oleksandr Zakapko

Deputy Chief

of Ivan Kozhedub Kharkiv

National Air Force University,

Kharkiv, Ukraine

https://orcid.org/0000-0001-6934-2568

Mykhailo Podrigalo

Doctor of Technical Sciences Professor

Chief Research

of National Academy of National

Guard of Ukraine,

Kharkiv, Ukraine

https://orcid.org/0000-0002-1624-5219

\author{
Kostiantin Yatsenko \\ Candidate of Technical Sciences \\ Senior Lecturer \\ of Ivan Kozhedub Kharkiv \\ National Air Force University, \\ Kharkiv, Ukraine \\ https://orcid.org/0000-0001-7822-8521
}

\title{
ВЫБОР РАЦИОНАЛЬНЫХ ПАРАМЕТРОВ РУЛЕВОГО ПРИВОДА ПЕРСПЕКТИВНОГО ТРАКТОРНОГО САМОХОДНОГО ШАССИ
}

\author{
А.Г. Закапко, М.А. Подригало, К.Г. Яценко
}

В данной статье на примере рулевого привода перспективного тракторного самоходного шасси проведен рациональный выбор геометрии рычажного механизма по критерию коэффициента полезного действия. Целью статьи является повышение коэффициента полезного действия рулевого привода тракторного самоходного шасси с передним поворотным мостом путем рачионального выбора его геометрических параметров. Определены угол начальной установки поворотного рычага. Получены аналитические выражения для определения хода штока силового гидроцилиндра и крутящего момента, создаваемого силовым гидроцилиндром. Определены работа сил трения в шарнире, который соединяет поворотный рычаг со итоком силового гидрочилиндра, что позволило определить ичиловой коэффициент потерь на трение в рулевом приводе. Определены значения рационального угла начальной установки поворотного рычага. Установлено, что при выбранном углу начальной установки поворотного рычага потери на трение в рулевом приводе снижаются. Применение рулевого привода с двумя силовыми гидрочилиндрами позволяет выровнять рабочие давления жидкости при повороте, как вправо так и влево, уменьшить иикловые потери на трение при угле начальной установки поворотного двухплечевого рычага.

Ключевые слова: тракторное самоходное шасси с поворотным передним мостом, поворотный мост, коэффициент полезного действия, рулевой привод, силовой гидроиилиндр, геометрические параметры рулевого привода. 


\section{SELECTING THE RATIONAL PARAMETERS FOR THE STEERING LINKAGE OF A PROSPECTIVE SELF-PROPELLED TRACTOR CHASSIS}

O. Zakapko, M. Podrigalo, K. Yatsenko

Tractor self-propelled chassis have become widely used in various industries and agriculture. In the Air Force of the Armed Forces of Ukraine these vehicles are used to repair the hard surfaces of airfields and can be used in the technological process of aircraft maintenance. Hydrovolumetric steering controls are used in the modern wheeled tractors including tractor self-propelled chassis. The steering gear is a traditional steering trapeze proposed by K. Benz in 1893. It is driven by a power hydraulic cylinder. The layout of the front axle of the self-propelled chassis allows it to rotate during the maneuver which ensures the movement of the left and right wheels without side sliding at any change in the track of the front wheels. In this article a rational choice of the geometry of the lever mechanism by the efficiency criterion is carried out on the example of the steering gear of a perspective tractor self-propelled chassis. The angle of the initial installation of the rotary lever is determined. The steering gear kinematic scheme is a vertical shaft of the front rotary axle gear at the upper end of which a rotary lever, connected to the power hydraulic cylinder, is set. The hollow space of the power hydraulic cylinder is connected with the metering pump of the hydro-volume steering. Analytical expressions for determining the stroke of the power hydraulic cylinder rod and the torque generated by the power hydraulic cylinder are obtained. The work of friction forces in the hinge connecting the rotary lever with the rod of the power hydraulic cylinder is determined. This allowed us to determine the cyclic coefficient of friction losses in the steering gear. It is determined for a perspective tractor self-propelled chassis that the rational angle of the initial installation of the rotary lever is $30^{\circ}$. The maximum values of the cyclic coefficient of friction losses in the steering gear can reach $4.3 \%$. At the selected angle of the initial installation of the rotary lever $30^{\circ}$, these losses reduce and stand for $2.2 \%$ when turning left and $0.35 \%$ when turning right. The usage of a steering gear with two power hydraulic cylinders allows to equalize the working pressures of the fluid when turning, both to the right and left, to reduce cyclic friction losses to $0.36 \%$ at the angle of initial installation of the rotary double-arm lever, that is equal to $0^{\circ}$.

Keywords: tractor self-propelled chassis with rotary front axle, rotary axle, efficiency, steering gear, power hydraulic cylinder, geometrical parameters of the steering gear. 